\title{
Sociedad del riesgo: producción y sostenibilidad
}

\section{Víctor Climent Sanjuán}

Universitat de Barcelona

vcliment@ub.edu

\section{Resumen}

El concepto sociedad del riesgo se basa en la constatación de que, en las sociedades actuales, la producción social de riqueza va acompañada por una creciente producción social del riesgo. La progresión y el aumento de estos riesgos está teniendo consecuencias políticas y económicas claras. Un primer efecto directo consistiría en la implementación de políticas gubernamentales orientadas al control y a la reducción de los mismos, como consecuencia directa de la mayor visibilidad que, para la opinión pública, tienen los problemas ambientales. De la misma manera que, desde una perspectiva económica, podemos establecer un claro paralelismo entre la teoría de la modernización ecológica y las nuevas estrategias ecoproductivas.

Este artículo pretende dar una visión general de todo este proceso partiendo del concepto sociedad del riesgo para, con posterioridad, establecer paralelismos con las nuevas estrategias ecoproductivas, con el proceso de modernización ecológico y con una última reflexión: ¿caminamos hacia un nuevo modelo productivo?

Palabras clave: riesgo, sostenibilidad, produccion, estrategias.

\section{Abstract. Risk society. Production and environment}

The concept of risk society is based on the fact that in current societies the production of social richness is aligned with a growing social production of risk. The progression and increase of these risks is having clear political and economical consequences. A first direct effect consists in the implementation of governmental policies oriented to the control and reduction of risks, as a direct consequence of the greater visibility that environmental problems have for the public opinion. In the same way that, from an economic perspective, we can establish a clear parallelism between the theory of ecological modernization and the new ecoproductive strategies.

This article intends to provide a general view of the whole process, departing from the concept of risk society, and establishing later parallelisms with the new eco-productive strategies, the process of ecological modernization and a last reflection: are we walking towards a new productive model?

Key words: risk, environment, production, strategy. 


\section{Sumario}
1. Introducción
4. Conclusiones
2. Riesgo, peligros e incertidumbre.
Bibliografía
Algunos ejemplos
3. Riesgos productivos
y nuevas estrategias ecoambientales

\section{Introducción}

El concepto sociedad del riesgo, ampliamente definido por Beck, se basa en la constatación de que, en las sociedades actuales, la producción social de riqueza va acompañada sistemáticamente por una creciente producción social del riesgo. En las sociedades contemporáneas, una proporción bastante elevada de estos «riesgos» está directamente relacionada con la tecnología y el sistema productivo, y se caracteriza porque trata de riesgos difícilmente detectables por los sentidos humanos. La contaminación química, la modificación genética de organismos o los efectos del cambio climático son algunos ejemplos de nuevos riesgos ambientales que se vienen a sumar a las terribles consecuencias provocadas por la contaminación industrial en las últimas décadas del siglo XX. Sin embargo, el análisis no sería completo si no añadiéramos a la lista de riesgos, el peligro latente de ruptura social que la globalización y los nuevos procesos de transformación económica están provocando en el seno de nuestra sociedad.

La progresión y el aumento de estos nuevos riesgos está teniendo consecuencias políticas claras. Un primer efecto directo consistiría en la implementación, por parte de los gobiernos, de políticas orientadas al control y a la reducción de los riesgos. Sin embargo, no cabe descartar un segundo efecto, de mayor calado que el primero, que está directamente relacionado con el fracaso de dichas políticas de control y con la opacidad informativa que, generalmente, practican los gobiernos y que, forzosamente, conduce a la deslegitimación de las instituciones públicas. Por lo tanto, es plausible afirmar que la sociedad del riesgo se origina allí donde los sistemas normativos y las instituciones sociales fracasan a la hora de conseguir la necesaria seguridad ante los peligros desencadenados por la toma de decisiones. Toda decisión debe guardar un escrupuloso equilibrio entre los beneficios devengados y los posibles riesgos y, por supuesto, debe incluir suficientes garantías de seguridad y de transparencia para evitar que ésta sea refutada públicamente. A modo de ejemplo, la decisión de alejar el Prestige de las costas gallegas (noviembre de 2002), fue un tremendo error, no sólo por su improvisación, sino, sobre todo, por el incumplimiento de las precauciones mínimas de seguridad y por la opacidad en la acción de gobierno, y tuvo como consecuencia el mayor desastre natural que ha sufrido la costa española a lo largo de este siglo.

Ahora bien, tampoco hemos de perder de vista que la sociedad del riesgo es una construcción social, que, más allá de la probabilidad, transmite a la socie- 
dad una sensación de riesgo difuso, de incertidumbre general que implica que la percepción social del riesgo sea mucho más acusada que el impacto objetivable. La ciudadanía percibe que los riesgos son crecientes y, a la vez, intuye que a las instituciones públicas les resulta cada vez más difícil dominar y controlar los riesgos, lo que provoca un creciente estado de preocupación y desconfianza social hacia los poderes públicos que, de nuevo, retroalimenta la percepción social del riesgo.

Este círculo vicioso que aviva la sensación de inseguridad puede ser, en parte, superado si, como afirman Lemkow y Espluga, aceptamos que el riesgo cero no existe e interiorizamos que es imposible eliminar o controlar todos los riesgos, sea cual sea su naturaleza (ambientales, sociosanitarios, laborales, etc.). Llegados a este punto, sería necesario redefinir el papel del Estado en esta materia y ser conscientes que ningún gobierno es capaz de garantizar la seguridad absoluta, ni siquiera pretenderlo. En cambio, sí que sería deseable exigir a los gobiernos que la toma de decisiones para gestionar los riesgos fuera más justa y democrática y, sobre todo, más transparente. Es decir, el énfasis debe recaer no tanto en la responsabilidad por no haber evitado un riesgo -que también-, sino en la gestión del proceso de crisis y en la transparencia de la toma de decisiones. En este sentido, el fortalecimiento del estado constituye una variable indispensable que contribuye a evitar la proliferación de riesgos, siempre y cuando genere mecanismos de control eficaces y evite que la toma de decisiones se vea empañada por la opacidad y la manipulación que, indefectíblemente, conduce a la impunidad con la que actúan muchas instituciones, tanto públicas como privadas.

\section{Riesgo, peligros e incertidumbre. Algunos ejemplos}

\subsection{La percepción de la crisis ecológica}

El estado del medio ambiente ocupa, desde hace años, un lugar visible en la lista de asuntos de interés para la opinión pública. Las cuestiones ambientales «han dejado de ser materia de preocupación casi exclusiva de grupos minoritarios más o menos radicales, para convertirse en problemas de importancia general»(Garcia Ferrando, 1991: 176). Como muestra la tabla 1, la preocupación por el medio ambiente se sitúa sólo después del desempleo y el orden público, y en niveles similares a las cuestiones relativas a la desigualdad social.

En las sociedades contemporáneas, la población percibe el deterioro del medio ambiente como un problema serio y preocupante. Ahora bien, el medio ambiente está presente en la sociedad como un concepto genérico, con multiples manifestaciones que dependen, entre otras cosas, del grado de información, de la presencia de los problemas en los medios de comunicación o de la proximidad o lejanía o de la gravedad o incertidumbre del hecho ambiental (García, 2004). Por ello, no es de extrañar que, aún entre un amplio sector de la población, la expresión medio ambiente o ecología sugiera la visión de jóvenes 
Tabla 1. Áreas de acción prioritaria para el Parlamento Europeo 1999 (\%).

\begin{tabular}{ll}
\hline Empleo & 55 \\
Lucha contra el tráfico de drogas & 36 \\
Protección del medio ambiente & 25 \\
Política exterior y seguridad & 25 \\
Política económica & 24 \\
Derechos humanos en el mundo & 21 \\
Lucha contra el cáncer y el sida & 20 \\
Política social & 17 \\
Política monetaria & 17 \\
Política de inmigración & 14 \\
\hline
\end{tabular}

Fuente: Eurobarómetro (1999).

ecologistas luchando desde sus lanchas neumáticas contra enormes buques que lanzan al mar residuos peligrosos, o nos remita a los maravillosos paisajes de la sabana africana o de la selva amazónica. En cambio, nos cuesta relacionar medio ambiente con producción o relaciones industriales y, a lo sumo, vinculamos la degradación del hábitat natural con la industria, al señalarla como la principal fuente de contaminación. Pero, acto seguido, nos tranquiliza pensar que la contaminación será, en un futuro próximo, controlada por la ciencia y la tecnología y que, por lo tanto, no cabe preocuparnos en exceso por ella.

Esta percepción de lo ecológico, que no es ajena a la influencia de los medios de comunicación, supone, en ocasiones, que la crisis se perciba como algo distante o lejano de nuestro modo de vida. Los desastres ecológicos se adivinan como algo tangible y real, pero que se materializa, en muchos casos, a miles de kilómetros de distancia, sin que sea posible distinguir culpables claros. En cambio, la destrucción de la capa de ozono o el cambio climático son realidades que preocupan, pero que, a diferencia de las anteriores, son interpretadas por la opinión pública como algo intangible, poco visible y muchas veces incomprensible por el lenguaje técnico que utilizan los expertos en la materia. $Y$ aunque los ecologistas nos digan, y numerosos institutos científicos lo corroboren $^{1}$, que las principales causas de esos fenómenos parten de nuestras industrias, nuestros automóviles y nuestro modelo de consumo, nosotros seguimos percibiendo que es algo que no nos afecta directamente, que encaja en la feno-

1. El Panel Intergubernamental para el Cambio Climático (IPCC) fue convocado por la ONU en 1988 para que los climatólogos de todo el mundo estudiasen el problema del clima. En 1990 , concluyen que existe un riesgo de calentamiento debido a la acción de los gases invernadero $\left(\mathrm{CO}_{2}\right.$, metano, óxido nitroso, etc.). En 1996 y, sobre todo, en el 2001, el IPCC convierte la posibilidad en certeza y señala la actividad humana como uno de los factores que mayor responsabilidad detenta en el calentamiento global del planeta. 
menología de los riesgos de grandes consecuencias ${ }^{2}$ (Giddens, 1996) y que, sobre todo, no existe ninguna prueba que permita visualizar las consecuencias de su actividad.

En este contexto difuso, que adolece de evidencias contrastables, y que se inscribe en un marco social donde aún sigue prevaleciendo la vieja visión de progreso heredada de la Revolución Industrial, es difícil percibir las consecuencias de la crisis en el propio territorio y exigir responsabilidades. Éstas, sin duda, existen, pero se diluyen en el conjunto de la sociedad y quizás, por ello, los empresarios admitan con naturalidad la existencia de la crisis ecológica, aunque sin dramatismos, y asuman que la industria ha sido una de las principales causas de la contaminación, pero sin olvidar que el beneficio de la producción no sólo se ha materializado en ganancias empresariales, sino que también se ha trasladado al consumidor que ha visto, en las últimas décadas, aumentar de manera muy intensa su nivel de vida. Esta traslación de responsabilidades al conjunto de la sociedad es una constante que halla aceptación por parte de todos, al admitir como legítimo el hecho que el progreso genera unos costes ecológicos indisociables al incremento de nuestra capacidad de consumo.

Por esta razón, no es de extrañar que los grandes grupos empresariales, que reconocen la globalidad del problema y la necesidad de buscar soluciones, sigan identificando crisis con grandes catástrofes ecológicas y señalen, como uno de los principales factores del deterioro del medio natural, el explosivo incremento demográfico de los países subdesarrollados. En cambio, es significativo que no elaboren crítica alguna al desarrollo industrial capitalista practicado en el Tercer Mundo, ni a los enormes traumas ecológicos que, en esos lugares, provoca la puesta en marcha del modelo tradicional de crecimiento industrial, mientras que sí justifican la inevitabilidad del deterioro ambiental como consecuencia del desarrollo económico experimentado por dichos países.

En cambio, desde la parte social, los sindicatos esgrimen una visión crítica de la crisis ambiental, y aunque su análisis a corto plazo no sea especialmente alarmista, sí muestran conciencia de que ésta irá en aumento si no se toman medidas urgentes que contribuyan a recomponer el equilibrio del medio natural. Los sindicatos, a diferencia de las organizaciones empresariales, señalan que la crisis ecológica no se circunscribe únicamente al marco industrial, sino que sus efectos indican la existencia de una crisis de modelo que afecta a las formas de producción y de consumo. Es la manifestación de una crisis social, que no únicamente obliga a los países desarrollados a poner en práctica una producción más limpia y a revisar la base tecnocientífica que sustenta el proceso productivo, sino que, además, plantea la necesidad de variar los hábitos de consumo, dotando de utilidad a todo aquello que compramos y consumimos.

2. Giddens define los riesgos de grandes consecuencias como incertidumbres fabricadas por la ciencia y la tecnología, cuyas inferencias son imprevisibles y cuya realidad siempre es negada o relativizada por las autoridades gubernamentales y los expertos en la materia (Giddens, 1996). 


\subsection{La percepción de los riesgos sobre la salud}

En las sociedades occidentales, existe una clara percepción de peligro sobre aquellos riesgos que afectan directamente a la salud de las personas y que, en los últimos tiempos, se ha incrementado preocupantemente como consecuencia de los desastres, los escándalos y los nuevos riesgos ambientales que amenazan a la salud pública. La enfermedad de las «vacas locas», las dioxinas o los preocupantes niveles de mercurio que contiene el pescado que consumimos, son realidades que contribuyen a que la sociedad interiorice una sensación de inseguridad ambiental y de incertidumbre cotidiana cada vez más amplia, que, paradójicamente, es una consecuencia no deseada del modelo productivo y cuyo origen se encuentra en la aplicación de tecnologías poco respetuosas con el medio natural y en la nula ética social de determinadas decisiones empresariales.

Los problemas ecológicos y los riesgos ambientales contemporáneos no son, en general, observables a simple vista, y requieren la intervención de técnicas caras y sofisticadas para su detección. Quedan muy lejos los densos y malolientes smogs de las primeras ciudades industriales. Los nuevos riesgos asociados con contaminantes como los pesticidas sintéticos (DDT o PCB), los metales pesados (mercurio, cadmio o plomo) o las radiaciones ionizantes (procedentes de las centrales nucleares o de las pruebas con armamento nuclear), son generalmente invisibles e inodoros y tienden a acumularse en el ecosistema y a ascender por la cadena alimentaria, afectando a grupos sociales que habían salido prácticamente indemnes del impacto ambiental provocado por la primera etapa industrial (Lemkow, 2002). Estos grupos sociales, y muy significativamente las clases medias y, también, la clase alta, empiezan a sentirse, por primera vez, vulnerables frente a los cambios cualitativos del medio ambiente, hecho que refuerza, por una parte, el sentimiento de indefensión e inseguridad que el carácter globalizador y transfronterizo de los nuevos riesgos provoca y que, por otra parte, facilita el auge de movimientos ambientalistas con una clara composición social de clase media.

En este sentido, es muy interesante la lectura del siguiente ejemplo, ya que ilustra con claridad el carácter interclasista de los nuevos riesgos ambientales: en la población japonesa de Minimata, durante los años cincuenta i sesenta, cerca de cuatrocientas personas murieron o sufrieron daños neurológicos irreversibles que finalmente fueron atribuidos a un proceso de envenenamiento por mercurio metílico ${ }^{3}$. Después de diversas investigaciones, se pudo comprobar que el mercurio procedía de una fábrica de productos químicos cercana a las zonas lacustres. Los peces, y especialmente la luciperca y la perca, que son especies que, debido a su escasez y alto precio, están destinadas al merca-

3. Los compuestos orgánicos del mercurio y de otros metales pesados son ingeridos y, generalmente, no excretados por la mayoría de organismos, de manera que, a pesar de un consumo extremadamente bajo, y tras un largo periodo de tiempo, la acumulación de dichos metales es lenta pero constante. 
do de bienes de lujo, absorbieron durante años grandes cantidades de mercurio que luego transmitieron a la población a través de su consumo. Un caso parecido ocurrió en Suecia (mucho menos grave) con especies piscícolas similares y, también, con faisanes que, involuntariamente, ingerían semillas tratadas con mercurio para prevenir determinadas plagas. El aspecto más destacable de ambos casos es que, además de las comunidades rurales que dependían del pescado de agua dulce para satisfacer en parte su régimen alimenticio, eran los sectores más opulentos de la sociedad japonesa y sueca los que tenían más posibilidades de contraer enfermedades, ya que estos productos contaminados estaban reservados al mercado de lujo. La respuesta no se hizo esperar: se paralizaron los vertidos de mercurio, se exhortó a una revisión del uso de mercurio en la agricultura y en la industria química y la fuerte movilización social, con un marcado protagonismo de las clases medias y altas, facilitó la aprobación de una legislación ambiental mucho más estricta (Lemkow, 2002).

En este contexto es donde debemos situar las crecientes inquietudes públicas ante la fabricación y comercialización de determinados productos y cuyo caso más paradigmático es la biotecnología basada en la ingeniería genética. Los avances espectaculares que esta disciplina ha protagonizado a lo largo de las últimas décadas son, en parte, responsables del intenso debate público generado sobre las implicaciones éticas, ambientales, sociales y económicas derivadas de la modificación genética de genes, microorganismos, animales y plantas. La respuesta social a estas prácticas está siendo muy compleja y ambivalente. Los estudios sobre aceptación pública de la ciencia muestran que la población es netamente favorable a la ciencia, aunque «pueden darse discrepancias específicas en cuestiones concretas» (Yoxen y Green, 1989), y la biotecnología y, especialmente, la ingeniería genética es un campo abonado de «discrepancias específicas». Es evidente que el potencial económico de la biotecnología es muy grande y que su aportación a la resolución de problemas de diagnóstico terapeútico o alimenticio puede ser muy elevada. Sin embargo, también es cierto, y así lo han puesto de manifiesto muchos estudios, que la ingeniería genética suscita preocupaciones de carácter medioambiental y ético. De hecho, amplias capas de la sociedad, especialmente las más «informadas», perciben la investigación genética como un agente de inseguridad ambiental apenas controlado por las instituciones públicas, que puede provocar efectos negativos en la salud pública y que, en última instancia, atesora un componente ético, en ocasiones, muy discutible, hasta el punto que algunos de sus detractores sitúan la investigación genética a las puertas del universo huxliano de un Mundo feliz ${ }^{4}$.

Entre las diversas variables barajadas, la regulación es, sin lugar a dudas, uno de los elementos clave a tener cuenta. Es evidente que el marco regulador actual contrasta vivamente con el existente en la década de los sesenta y setenta. La irrupción de las nuevas tesis neoliberales a partir de mediados de los

4. El Mundo feliz (Huxley, 1976) constituye una de las obras cumbres de la literatura de ciencia ficción y una de las más brillantes antiutopías donde todo parece quedar al alcance de la tecnología de los genes. 
años ochenta, ha supuesto la vuelta a unas prácticas económicas donde la desregulación y la flexibilización son la clave del crecimiento económico y del progreso social. La aceptación de estos principios por parte de la mayoría de países desarrollados está generando una creciente preocupación pública acerca de la falta de regulación y control, por parte del estado, de aquellas actividades económicas que pueden tener implicaciones graves sobre el equilibrio ecológico y la salud pública. Diversos estudios muestran que esta preocupación es bastante independiente del posicionamiento ideológico de los individuos, y señala que la mayoría está a favor de incrementar los controles en lo que se considera dos campos vitales: la salud pública y el medio ambiente. La enfermedad de las «vacas locas», el uso de hormonas ilegales para el ganado o el desastre del Prestige, son hechos que ponen en entredicho los actuales sistemas de regulación y control, que cuestionan el excesivo adelgazamiento de la estructura del estado y que, en última instancia, minan la confianza pública en la capacidad de los gobiernos para hacer frente a los nuevos riesgos ecológicos.

\subsection{Los nuevos riesgos laborales: desregularización y precarización}

Sin embargo, la sociedad del riesgo no únicamente está relacionada con los aspectos ecológicos, biotecnológicos o alimentarios, sino que también mantiene una estrecha relación con los riesgos laborales, que, históricamente, han estado muy relacionados con la salud laboral y con el grado de accidentalidad dentro del espacio de trabajo. Durante la primera industrialización (siglo XIX y primer tercio del siglo XX), existe una clara percepción social que considera que el riesgo laboral es un hecho inevitable y atribuible casi en exclusiva al trabajador, que es señalado como el principal responsable de su salud y seguridad laboral. A lo largo de este periodo, trabajo y riesgo no parecen estar relacionados y los accidentes sólo son atribuidos a la fatalidad o a la temeridad de los obreros.

El desarrollo económico y social experimentado por las sociedades occidentales a lo largo del siglo XX, ha contribuido a una mejora significativa de las condiciones sociolaborales de los trabajadores y a un avance sustantivo de la seguridad en el trabajo. La teorización sobre los factores técnicos y humanos que pueden provocar los accidentes laborales, la implicación de los empresarios en la prevención de los riesgos laborales y la aparición de técnicos en prevención laboral, son factores que, indiscutiblemente, han permitido disminuir la accidentalidad y mejorar la seguridad en el trabajo.

No obstante, la progresiva implantación de la globalización económica y de sus políticas desreguladoras ha promovido, en las últimas décadas, una serie de cambios políticos, económicos y sociales que están teniendo efectos muy negativos sobre el ámbito laboral, y que ha provocado la aparición de nuevos riesgos sociolaborales derivados de las múltiples formas de precariedad y segmentación laboral. La flexibilización de la producción como medio de adaptación a la creciente diversidad de la demanda o la descentralización productiva, que promueve el desarrollo de nuevas formas de trabajo muy relacionadas con la subcontratación interna y externa, como, por ejemplo, la proliferación de 
ETT o la creciente contratación de trabajadores autónomos para tareas propias de asalariados, son buenos ejemplos del tipo de estrategia que las empresas emplean como respuesta a la creciente mundialización de los mercados y que, indefectiblemente, generan formas cada vez más regresivas de relación laboral.

En el caso español, la creciente flexibilidad productiva y las altas tasas de paro registradas hasta principios de los años noventa, han derivado en una preocupante precarización del mercado de trabajo, con índices de temporalidad superiores al $30 \%$ sobre el total de asalariados, como podemos observar en la tabla 2.

La alta rotación de los contratos, la escasa formación y la poca implicación del trabajador en la empresa, son factores que explican el creciente abandono de las políticas de prevención por parte de las empresas y que ayudan a entender el fuerte incremento de la accidentalidad laboral experimentado en los últimos años. Sin embargo, hemos de ser conscientes que este intenso proceso de desregulación y de precarización del mercado de trabajo, además de contribuir al incremento de la accidentalidad laboral (tabla 3), tiene consecuencias mucho más profundas.

Tabla 2. Asalariados por tipo de contrato (en tantos por ciento).

\begin{tabular}{lll}
\hline Año & Fijos & Temporales \\
\hline 1987 & 84,4 & 15,6 \\
1989 & 73,3 & 26,7 \\
1991 & 66,5 & 33,5 \\
1993 & 67,8 & 32,2 \\
1995 & 65,0 & 35,0 \\
1997 & 66,7 & 33,3 \\
2000 & 67,9 & 32,1 \\
2002 & 69,3 & 30,7 \\
2004 & 69,9 & 30,1 \\
\hline
\end{tabular}

Fuente: EPA, 1987-2004.

Tabla 3. Evolución de los accidentes laborales graves con baja y con resultado de muerte en Cataluña.

\begin{tabular}{lll}
\hline Año & Acc. laborales graves & Con muerte \\
\hline 1998 & 1.579 & 158 \\
1999 & 1.666 & 180 \\
2000 & 1.487 & 151 \\
2001 & 1.700 & 155 \\
2002 & 1.685 & 186 \\
2003 & 1.601 & 149 \\
\hline
\end{tabular}

Fuente: Conselleria de Treball (2004). 
En primer lugar, potencia una dinámica de externalización del riesgo económico, que antaño recaía en exclusiva en el empresariado, y que ahora, a través de la precariedad y la temporalidad, se transfiere y comparte con los trabajadores asalariados. En la actualidad, las empresas, al más mínimo contratiempo económico, prescinden con rapidez de la mano de obra temporal. Es un método de ajuste económico rápido ante cualquier contingencia que suponga un desvío de las previsiones empresariales, pero es una estrategia que, desde el punto de vista social, tiene costes muy importantes, tales como: la pérdida de seguridad en las condiciones de trabajo o la rápida aparición de cuadros psicológicos de angustia e incertidumbre personal que, entre otras consecuencias, impiden a los afectados la elaboración y plasmación de proyectos de futuro.

En segundo lugar, facilita el crecimiento de los procesos de individualización en las relaciones laborales que tienen como objetivo convertir al trabajador en su "propio centro de trabajo». En este sentido, las empresas se aprovechan claramente de un valor muy arraigado en el seno de las «viejas clases medias» y que, también, es muy apreciado por la clase trabajadora: el valor de la independencia y el deseo de ser tu "propio amo", para alcanzar ingresos económicos más elevados y mayores cotas de autorrealización. Esta realidad, afecta especialmente a los trabajadores autónomos que, en las dos últimas décadas, han experimentado un crecimiento espectacular en España que, en parte, puede ser justificado por la aparición de nuevas oportunidades económicas, pero que, sobre todo, se debe a la creciente dificultad que muchas personas encuentran para contratarse como asalariados. En última instancia, estas nuevas formas de trabajo tienen una característica común: la mayoría de estas personas, bajo el disfraz del «trabajo autónomo» han sido expulsadas del modelo tradicional de relaciones laborales y, consecuentemente, han perdido la seguridad y buena parte de sus derechos laborales.

\subsection{La precarización como nuevo riesgo laboral}

El concepto precarización aplicado al ámbito laboral es un término que suele referirse a la creciente importancia del empleo temporal en el conjunto del empleo asalariado. Y aunque su interpretación es muy amplia, puede definirse como un proceso genérico de degradación de las condiciones sociolaborales. En este sentido, la observancia de los fenómenos sociales dentro del campo laboral parece evidenciar que existe un claro paralelismo entre estabilidad laboral y buenas condiciones socioeconómicas, mientras que la temporalidad se corresponde, generalmente, con la pérdida de expectativas laborales, menor retribución, escasas posibilidades de promoción y un mayor riesgo de accidentalidad laboral. En otras palabras, la temporalidad en el trabajo lleva aparejada, generalmente, una degradación de las condiciones laborales propia de la contratación indefinida, sin que medie entre ambos diferencias notables de cualificación o experiencia en el trabajo.

Desde una perspectiva social, la desregulación del mercado de trabajo ha contribuido a intensificar las desigualdades existentes en la estructura social, 
ha generado una mayor inestabilidad laboral que ha castigado especialmente a los colectivos más débiles y, en última instancia, ha consolidado, a través de un mercado secundario que se nutre de jóvenes, mujeres y trabajadores no cualificados, la reproducción de pautas sociales discriminatorias.

En cambio, desde el campo empresarial, el recurso a la temporalidad y el abuso en la sustitución de trabajadores fijos por temporales, ha sido justificada por razones estructurales. Para muchas empresas, el recurso a la contratación temporal ha permitido reducir costes y obtener precios más competitivos en un mercado cada vez más exigente. Es decir, determinados sectores empresariales han apostado claramente por un marco competitivo basado en los bajos costes salariales, con la consiguiente renuncia a adoptar una estrategia de futuro verdaderamente sólida y sustentada en la mejora de la calidad de los productos, en la incorporación de nuevas tecnologías y, sobre todo, en la formación y calificación de sus trabajadores.

En última instancia, las nuevas formas de contratación temporal han sido incapaces de alcanzar otro de los objetivos para las que fueron diseñadas: la erradicación de las grandes bolsas de trabajo sumergido que caracterizan a nuestro sistema productivo. En un gran número de casos, la temporalidad ha tendido a combinarse con el trabajo sumergido, lo que ha provocado que muchos trabajadores alternen contratos temporales con periodos de trabajo sumergido, en función de la coyuntura económica y de la cuenta de resultados de la empresa. Esta práctica, relativamente usual en las empresas de pequeño tamaño, e indirectamente propiciada por la gran empresa a través de la subcontratación, ha contribuido al crecimiento de un segmento marginal, a caballo entre la economía legal y la sumergida, que constituye una oferta de mano de obra muy flexible que acepta, con gran resignación, condiciones de trabajo irregulares o muy cercanas a la frontera de la ilegalidad.

\section{Riesgos productivos y nuevas estrategias ecoambientales}

\subsection{La "modernización ecológica» 5}

Esta teoría, originaria del sociólogo alemán Joseph Huber, entiende la modernización ecológica como la tercera y última fase del desarrollo histórico de la sociedad industrial de Europa occidental. Básicamente, este concepto que aparece a partir de la década de los ochenta, presupone una nueva lectura de los principios tradicionales del sistema industrial y productivo, que, en su proceso evolutivo, va incorporando las nuevas teorias ecológicas. Asimismo, la teoría de la modernización ecológica ha sido desarrollada por otros autores, prin-

5. Ver: Geert SPAargaren y Arthur P. J. Mol (1992). «Sociology, Environment, and Modernity: Ecological Modernisation as a Theory of Social Change». Society and Natural Resources, 5: 323-344; Arthur P. J. Mol (1995). The refinement of Production: Ecological Modernization Theory and the Chemical Industry. Utrecht, Holanda: International Books; Peter CHRISTOFF (1996). «Ecological Modernisation, Ecological Modernities». Environmental Polítics, 5(3): 476-500. 
cipalmente alemanes y holandeses, como Arthur Mol (1995), que aplica el marco conceptual de estos principios teóricos para analizar y explicar los cambios acaecidos durante los últimos años en la industria química. Para este autor, la ciencia está adquiriendo un gran protagonismo en las nuevas estrategias industriales, de la misma manera que los procesos de producción y consumo se fundamentan con mayor frecuencia en criterios ecológicos tales como: el análisis del ciclo de vida de los productos, el reciclaje o las nuevas tecnologías verdes. En este contexto, las ONG ambientalistas también han experimentado un cambio importante en sus estrategias, sustituyendo paulatinamente la confrontación por el diálogo y la negociación directa con los agentes económicos. Por último, y éste es un punto muy importante a tener en cuenta, ante los crecientes problemas ambientales causados por la industria, la modernización ecológica se erige como un modelo alternativo al proceso de desindustrialización que, como consecuencia de sus repercusiones económicas y laborales, goza de muy poca aceptación popular.

Sin embargo, también es preciso destacar la existencia de voces críticas que afirman que los teóricos de la modernización ecológica dibujan un panorama excesivamente optimista del proceso de cambio y de la evolución de la sociedad industrial, valga como ejemplo la visión pesimista de Beck, e incluso llegan a afirmar que el marco conceptual de la modernización ecológica puede llegar a legitimar, en parte, la persistente degradación ambiental derivada del consumo y de la producción industrial de masas. Es una visión, evidentemente, crítica con la teoría de la modernización ecológica que, además, considera que las bases teóricas propuestas tienen poca correspondencia con la realidad del proceso evolutivo industrial y productivo de la sociedad moderna.

\subsection{Principales estrategias ecoproductivas}

El rápido desarrollo tecnológico y científico de las últimas décadas, ha provocado un intenso proceso de crecimiento económico del capitalismo, que, paralelamente, ha propiciado la aparición de nuevas formas de concienciación y de percepción social del riesgo ante los numerosos daños que el sistema productivo está provocando a nuestro planeta. Los grandes grupos empresariales, conscientes de esta realidad, no han tardado mucho en elaborar nuevas estrategias tendentes a mejorar su imagen y a disminuir el impacto de su actividad sobre el medio natural.

Desde mediados de los años ochenta, las políticas ambientales han ido ganando peso en el diseño de las estrategias empresariales. Desde luego, el medio ambiente no ha logrado el rango prioritario que poseen otras áreas de la actividad empresarial (producción, finanzas...), pero la realidad ecológica, en mayor o menor medida, parece que empieza a formar parte de los principales ingredientes de una correcta receta empresarial.

La nueva normativa ambiental emanada desde la Unión Europea, el Gobierno central y los gobiernos autónomos ha ejercido, en los últimos años, una influencia notable sobre las estrategias empresariales, no sólo por su carác- 
ter punitivo, sino, también, porque indica una dirección clara, una estrategia ambiental de futuro que todas las empresas deberán adoptar, a medio y largo plazo, si no quieren quedar excluidas del mercado. En este sentido, el avance más significativo ha sido la implantación en muchas empresas de una estrategia común de eliminación de residuos industriales. Este proceso, que a simple vista no parece revestir mucha importancia, constituye en sí mismo un paso decisivo en la normalización de la gestión ambiental de las empresas, puesto que, por una parte, supone un firme avance hacia una práctica legal de la gestión de los residuos industriales y, por otra, permite trasladar por primera vez al precio final del producto algunos de los costes ecológicos que, con anterioridad, siempre habían sido externalizados.

Esta práctica legal de la gestión de los residuos aún está lejos de alcanzar a la totalidad de las empresas, y constituye un primer paso que, necesariamente, debe conducir hacia objetivos más ambiciosos, como la aplicación de estrategias preventivas que ataquen en origen a los procesos contaminantes. La realidad muestra que pocas empresas han adoptado soluciones preventivas y que la mayoría se resiste a variar los procesos productivos si éstos no están suficientemente amortizados o si no contribuyen a reducir los costes de producción. En verdad, solamente los grandes grupos empresariales, que poseen un sistema de gestión ambiental más avanzado, ponen en práctica la estrategia preventiva, mientras que el grueso de las empresas difícilmente va más allá de lo prescrito por la ley si no va acompañado de una política clara de subvenciones, lo cual lleva a concluir que, aunque exista un número creciente de empresas que están dispuestas a incorporar tecnologías limpias en sus sistemas productivos, este proceso sólo se acelerará cuando su introducción compense económicamente a las empresas o si el estado refuerza el marco regulador.

La aplicación de una correcta gestión ambiental también supone un menor gasto de recursos primarios y energéticos y un mejor aprovechamiento de éstos. Esta mayor eficiencia productiva es valorada muy positivamente por las empresas y es uno de los argumentos que más influye en el desarrollo de las buenas prácticas ambientales. No obstante, no hemos de perder de vista que, para las empresas de mayor tamaño, además de la eficiencia productiva, existen otros factores que influyen significativamente en el diseño de la gestión ambiental.

En primer lugar, se suele relacionar buena gestión ambiental con competitividad empresarial, resaltando únicamente los aspectos positivos de este binomio. Sin embargo, en el campo empresarial, muchas veces pesan más los aspectos negativos que los positivos. Una correcta gestión ambiental puede constituir un factor positivo de competencia e, incluso, puede revertir en un incremento de las ventas, aunque su plasmación en la realidad es difícil de medir, porque en las estrategias comerciales de las empresas intervienen muchos factores, además del ambiental. Pero lo cierto es que una mala gestión ambiental necesariamente conlleva problemas que, a medio y a largo plazo, puede obligar a una empresa a tener que asumir responsabilidades económicas, administrativas e incluso penales. El marco legal vigente en los países desarrollados sanciona, con mayor o menor dureza, la contaminación del medio ambiente con 
multas e importantes indemnizaciones. Además, son acciones que provocan un fuerte rechazo social que, generalmente, siempre acaba lesionando los intereses económicos de las empresas y que, en casos extremos, puede significar un desplome bursátil ${ }^{6} \mathrm{o}$, incluso, puede entrañar el ingreso en prisión de directivos y empresarios ${ }^{7}$. Así pues, es la interpretación negativa la que tiene mayor peso en la argumentación general, no la positiva. Pesan más los problemas que se derivan de una mala gestión ambiental que los beneficios asociados a la misma. En este sentido, el creciente control por parte de la Administración, el aumento de la cuantía de las sanciones por actividades contaminantes y la inclusión en el nuevo código penal del delito ecológico, son elementos claramente disuasorios que influyen notablemente en la conducta ambiental de las empresas.

En segundo lugar, la imagen de empresa, la competitividad derivada de la implantación de tecnologías limpias y las nuevas oportunidades de negocio que brinda la economía verde, son factores que tienen una importancia creciente en las estrategias empresariales. Para las grandes empresas, la imagen es un elemento de vital importancia que está íntimamente relacionado con la competitividad. Las empresas, estén instaladas en suelo europeo, norteamericano o en países periféricos, necesitan mantener una buena imagen, porque sus principales mercados se localizan en los países desarrollados. Cualquier desliz ecológico, cualquier efecto negativo o perverso del que se hagan eco los medios de comunicación o las principales organizaciones ecologistas, puede entrañar una pérdida sustancial de cuota de mercado. Este nuevo escenario, inexistente hasta finales del siglo XX, ejerce un poderoso efecto disuasorio sobre las grandes corporaciones, especialmente las multinacionales, que las obliga necesariamente a compaginar imagen, competitividad y gestión ambiental.

En tercer y último lugar, el respeto al medio ambiente y la aplicación de una correcta gestión ambiental, no sólo permite una más elevada competitividad empresarial, sino que, además, se está convirtiendo en una importante barrera de entrada al mercado. La paulatina introducción de la ecoeficiencia y la búsqueda de nuevos métodos tecnológicos que reduzcan la emisión de contaminantes, son objetivos que responden a una sustantividad muy concreta que asume, por una parte, la existencia de un problema que debe resolverse y que, por otra, genera un conjunto de nuevas expectativas empresariales que están configurando un nuevo marco competitivo basado en una doble estrategia. La primera, descansa en el negocio emergente que representa la producción y comercialización de nuevas tecnologías más «limpias». Y la segunda, se deriva de la aplicación de las nuevas directivas comunitarias en materia ambiental, que, además de profundizar en la preservación del medio, están

6. La enorme contaminación causada en el entorno de Doñana por el desplome de la presa de contención de la mina de Aznalcóllar, provocó una caída bursátil superior al 20\% de la empresa propietaria, la sueca Boliden.

7. El ingreso en prisión, en 1997, del empresario Puigneró por delito ecológico es una muestra de ello. 
facilitando indirectamente la puesta en escena de un nuevo dispositivo competitivo que actúa como proceso de exclusión y que, a medio plazo, contribuirá a expulsar del mercado a aquellas empresas que no se adecuen a las nuevas prerrogativas ecocompetitivas.

\section{2. ¿Caminamos hacia un nuevo modelo productivo?}

La duda de si nos hallamos ante un proceso de interiorización de lo ecológico o, por el contrario, ante una inteligente estrategia de mercado, es uno de los interrogantes que nos podemos plantear con mayor insistencia. ¿Estamos viviendo la aparición de un modelo de producción con implicaciones ecológicas? o ¿no es más que una simple amalgama de mercadotecnia ecológica y de soluciones técnicas? Lo más probable es que estemos entrados en una fase de concienciación (relativamente) proambiental, por parte del colectivo empresarial, al tiempo que las estrategias productivas aún siguen caracterizándose por un escaso compromiso ambiental.

No obstante, a la luz de los datos y de las investigaciones realizadas, parece posible dibujar una tendencia de gran calado. La pesada maquinaria del sector productivo parece que empieza a moverse lentamente hacia una dinámica económica más respetuosa con el medio natural. Estamos ante un proceso de transición lento, asimétrico y con numerosos altibajos, donde unos sectores económicos avanzan con mayor rapidez, otros se encuentran en la "parrilla de salida» y, por supuesto, algunos siguen instalados en la práctica de actividades altamente contaminantes. Una prueba de esta mejor disposición ambiental, especialmente en el sector de la gran industria, es el marcado interés que ésta muestra por desvincular las nuevas prácticas ecológicas de las estrategias comerciales a corto plazo y por correlacionar positivamente gestión ambiental con estrategia de supervivencia y éxito de la empresa a largo plazo. Pero esta realidad no debe hacernos olvidar que siguen existiendo enormes diferencias entre las políticas ambientales aplicadas según el sector y el tamaño de la empresa, y que el marco regulador y la presión social son los principales o únicos estímulos que ejercen influencia sobre las estrategias productivas de muchas empresas.

Con toda seguridad, el principal motor de cambio de la industria y de las empresas procede de la propia sociedad (en especial, de la militancia ambientalista y ecologista) y tiene un carácter eminentemente sociocultural. En la España de hace treinta años, existía una plena identificación entre progreso económico e industrialización, y la externalización de los costes ecológicos generados por las industrias apenas provocaba rechazo. Es más, muchos estaban convencidos de que éste era el precio a pagar por el desarrollo económico. Sin embargo, en las últimas décadas, el panorama ha experimentado un profundo cambio. Por fin, la sociedad ha dejado de identificar desarrollo con industrialización y la ciudadanía se muestra cada vez más crítica e intolerante con la contaminación. Esta nueva percepción social está teniendo importantes repercusiones sobre el aparato productivo. Las industrias y las empresas en general, a riesgo de quedar apeadas de la competición, se estan viendo obliga- 
das a dar una respuesta satisfactoria a una nueva exigencia social: producir pero contaminando mucho menos. Muchas empresas, sobre todo las más grandes, empiezan a adoptar medidas ambientales correctoras con vistas a situarse en una posición de ventaja respecto a sus competidoras y, algunas, las menos aún, han empezado a comprender que la función socioecológica de las empresas será una de las claves futuras del éxito empresarial.

En este sentido, el nuevo marco competitivo es un elemento decisivo a la hora de analizar la integración de la esfera ecoambiental en la cultura de empresa, pero no el único. Por una parte, es necesario huir del engaño de la autorregulación de los sectores empresariales y reforzar la capacidad de control del estado, como único método para conseguir que todas las empresas respeten la normativa ambiental. Y, por otra parte, cabe esperar que, a largo plazo, la ciudadanía pueda exigir a las empresas un mayor esfuerzo en la preservación del medio natural (de hecho, ya se observan algunos indicios), de manera que es posible que, en el futuro, la pequeña o nula contaminación de las instalaciones productivas ya no sea una garantía de éxito, sino una exigencia de supervivencia empresarial.

\section{Conclusiones}

Es indudable que el intenso desarrollo económico que se ha producido a lo largo del siglo XX, ha transformado nuestras sociedades y ha permitido que gocemos de niveles de bienestar inimaginables a principios de siglo. Sin embargo, nuestro progreso social, fruto del proceso de modernización de la sociedad capitalista industrial, ha ido acompañado de un significativo incremento de «riesgos o peligros» consustanciales al propio desarrollo tecnoeconómico y a la producción de bienes y servicios.

A lo largo de la década de los ochenta, la sociedad del riesgo empieza a ser netamente percibida por una parte importante de la población, que presiona con fuerza a los poderes públicos para que los riesgos de la sociedad postindustrial sean objeto de un intenso debate social. La moratoria nuclear, la creciente legislación ambiental, el control de las emisiones contaminantes de vehículos e industrias o el endurecimiento de las normas de seguridad de la industria química, son algunos ejemplos que muestran como la sensación de inseguridad o de peligro experimentada por la población, ante amenazas que no controla, obliga a las instituciones públicas a tomar decisiones tendentes a reforzar la seguridad de los sistemas productivos.

En este contexto, el principio de precaución, formulado por primera vez en la Conferencia de Estocolmo de 1972 y que, en la actualidad, constituye uno de los principios rectores de la política ambiental de la Unión Europea ${ }^{8}$, viene a

8. El artículo 130.2 del Tratado de Maastricht indica: «La política de la UE en el ámbito del medio ambiente tendrá como objetivo alcanzar un nivel de protección elevado, teniendo presente la diversidad de situaciones existentes en las diferentes regiones de la UE. Se basará en los principios de precaución y de acción preventiva, en el principio de corrección de los 
decir, básicamente, que los problemas ecológicos y sanitarios, especialmente los de mayor repercusión, hay que preverlos de antemano e impedir que lleguen a materializarse, ya que muchos de ellos pueden tener un carácter irreversible e irreparable (Aguilar, 1997). La esencia del principio estriba en la necesidad de actuar anticipándose a los problemas, incluso en ausencia de pruebas concluyentes del daño y, sobre todo, si hay incertidumbre científica sobre los nexos causales en juego (Sempere, Riechmann, 2000). En este sentido, el principio de precaución puede constituir una adecuada política de seguridad preventiva, siempre y cuando prevalezca la precaución sistémica sobre la individualizada. Es decir, las políticas públicas deben rehuir las estrategias clásicas del riesgo que defienden la libre comercialización de productos, sin apenas trabas, si éstos superan unas pruebas limitadas en el espacio y en el tiempo que demuestren la no afectación a la salud pública o al medio ambiente. En cambio, la precaución sistémica es mucho más sostenible, porque está basada en escalas de tiempo mayores, en relativas certezas y en un espacio social y ambiental de mayor amplitud. La precaución tiene una relación directa con la seguridad, de manera que la falta de certezas científicas no debe usarse como razón para relajar los controles públicos o para postergar medidas que protejan nuestra salud o que impidan la degradación del medio natural. Más bien lo contrario, la precaución exige un estado activo, impone una actitud vigilante y estimula una prudente anticipación destinada a identificar posibles riesgos catastróficos.

Así pues, la clave de todo el proceso consiste en diseñar un modelo de desarrollo que permita combinar el crecimiento de la riqueza y del bienestar social con la preservación del medio natural y la asunción de unos niveles suficientes de seguridad ecológica, sanitaria y social. En este contexto, la idea del desarrollo sostenible, concepto que por primera vez puso de relieve la existencia de riesgos presentes y futuros como consecuencia de la actividad humana, puede facilitar la transición hacia un futuro modelo de sostenibilidad. Sin embargo, para que este tránsito llegue a buen puerto, es necesario tener presentes dos factores de gran calado.

En primer lugar, hemos de aceptar que toda actividad humana tiene un coste ambiental que, de una manera u otra, debe ser amortizado. La sociedad puede pagarlo con costes de prevención y de corrección de la actividad productiva, o bien costearlo a través del aumento del presupuesto sanitario o de las partidas destinadas a la recuperación y descontaminación de espacios naturales degradados. Es una cuestión de elección en la que todos debemos participar. Una posible respuesta, la más usual, consiste en la socialización de costes, de forma que la responsabilidad de la problemática ambiental y de la salud pública recae sobre el conjunto de la sociedad. De hecho, la mayoría de la población sigue asumiendo con naturalidad que la contaminación derivada del proceso productivo es una responsabilidad compartida, ya que todos nos

atentados al medio ambiente, preferentemente en la fuente misma, y en el principio de que "quien contamina, paga». 
beneficiamos de la riqueza generada por la producción y, por lo tanto, es plausible que sea la sociedad, a través de los presupuestos del estado, la que asuma los costes ambientales y sanitarios derivados del desarrollo económico y de la producción ${ }^{9}$. No obstante, parece mucho más lógico enfocar el debate desde una perspectiva diferente, que apueste por una fórmula que potencie las tecnologías limpias y que grave las producciones y los consumos de aquéllos que más contaminan, evitando, de esta forma, que sea el conjunto de la sociedad la que deba pagar los costes ambientales de la producción. En este sentido, una posible solución consistiría en la integración de los costes ambientales en el ciclo vital de los bienes de consumo, de manera que su precio refleje todos los costes, incluidos los ecológicos, con el objetivo de impedir su externalización.

En segundo lugar, cabe señalar que las pautas impuestas por los mecanismos de mercado configuran un modelo económico totalmente capacitado para limitar las emisiones contaminantes, para erradicar los vertidos incontrolados e, incluso, para adaptar las líneas productivas a un tipo de producción más limpia. Pero, en cambio, es un sistema incapaz de orientarse hacia la sostenibilidad, puesto que tiende a primar los intereses económicos a corto plazo en detrimento de las decisiones de interés general, que precisan del largo plazo. Los factores que alientan esta tendencia se fundamentan en tres principios: la resistencia de los mecanismos de mercado a interiorizar las externalidades negativas que él mismo genera, el escaso peso de la iniciativa política de los gobiernos, que se ve reducida al corto plazo por la dinámica electoral y las fuertes presiones ejercidas por los grandes grupos industriales y, en última instancia, el creciente abismo que separa la estructura de decisiones de la sociedad industrial y el carácter planetario de sus efectos secundarios. Esta disonancia, que genera lo que Beck define como sociedad mundial de riesgo, pone de manifiesto la incapacidad de los gobiernos para resolver el problema y evidencia una profunda crisis institucional de la «vieja» modernidad industrial de los estados nacionales (Beck, 1998).

Evidentemente, el estado desempeña un papel activo en el campo ambiental, aunque su aportación, a riesgo de incurrir en una excesiva simplificación, se limita a elaborar leyes orientadas a controlar y sancionar los niveles de contaminación y los vertidos incontrolados, además de crear la infraestructura necesaria para almacenar (vertederos), incinerar o potenciar la valorización y posterior recolocación de aquellos desechos que sean susceptibles de ser aprovechados. $\mathrm{Al}$ margen de estas consideraciones, y salvo alguna excepción, los estados toman pocas iniciativas y se muestran remisos a adoptar medidas de carácter político que reconduzcan la situación, por temor a colapsar el sistema económico. En realidad, esos mismos estados aceptan plenamente la vigencia del crecimiento eco-

9. Las miles de toneladas de residuos tóxicos depositados por Erquimia en el cauce del río Ebro o la montaña de residuos salinos procedentes de las minas de potasa de Sallent, son ejemplos gravísimos de contaminación provocados por empresas privadas, y cuya limpieza se financiará a través de dinero público. Es decir, dicha socialización de costes implicará que sea toda la sociedad la que, a partir de fondos públicos, financie la limpieza del foco de contaminación. 
nómico como único motor de bienestar, y encubren en la compleja coordinación de las políticas ambientales de ámbito mundial, la evidente subyugación de lo político y lo social a lo económico, que deja en manos de las empresas, la tecnología y el mercado la resolución de los desequilibrios ecológicos.

Esta falta de reflejos de los organismos públicos, que se repite en otros órdenes, como el empleo, tiene como principal consecuencia la pérdida de la iniciativa política a manos de grandes grupos industriales y financieros, que, a través de la globalización económica, influyen de manera poderosa, tanto en las políticas económicas como en los procesos de desregulación de las economías occidentales, lo que genera situaciones no exentas de graves riesgos ambientales.

La pujanza y el crecimiento de estos grupos empresariales, en un contexto económico mundializado, entraña el riesgo de una subordinación clara de las políticas públicas ambientales a unos determinados intereses económicos que, incluso, pueden llegar a condicionar los ritmos y los objetivos diseñados por los gobiernos en esta materia. A modo de ejemplo, es evidente que, si no media una intervención política contundente, las industrias petroleras o las eléctricas difícilmente desarrollaran de motu proprio programas serios de investigación en nuevas energías alternativas. Más bien lo contrario, presionarán a todas las instancias políticas posibles para impedir cualquier paso hacia delante, como ha sucedido con la negativa de la Administración Bush a ratificar el Protocolo de Kioto. La experiencia demuestra, y existen múltiples ejemplos de ello, que solamente cuando existe una norma que obliga, en una fecha determinada, a reemplazar un determinado tipo de energía por otra, es factible iniciar un proceso de sustitución. En cambio, si la sociedad y el poder político depositan, en los mecanismos de mercado o en las empresas, la responsabilidad de la iniciativa ambiental, nos podemos encontrar con que los progresos en esta materia avancen al ritmo que el sector económico determine, y no en función de la disponibilidad técnica o de las necesidades sociales del momento.

Es evidente que, muchas veces, los estados se muestran impotentes para hallar soluciones, porque anteponen los intereses nacionales a los de carácter mundial y porque la resolución del problema pasa necesariamente por la creación de instituciones supranacionales que tengan capacidad, no solamente para sancionar los comportamientos ecológicamente incorrectos, sino también para iniciar un proceso de reflexión sobre las bases del modelo económico y de las instituciones en general. Una buena prueba de estas limitaciones la encontramos en los continuos fracasos de las cumbres ambientales celebradas hasta el momento presente y que, salvo algunas excepciones ${ }^{10}$, siempre han finalizado con declaraciones de escaso contenido político que, al cabo de los años, deben ser revisadas a la baja para poder permitir que las naciones más desarrolladas y más contaminantes se avengan a suscribir un nuevo acuerdo

10. Un buen ejemplo sería el Protocolo de Montreal (1987), que regula la desaparición de las emisiones de CFC durante el periodo 1996-2010, o el Tratado de la Antártida (1993), que prohíbe hasta el 2040 cualquier actividad minera en el continente. 
que, probablemente, volverán a incumplir en el futuro ${ }^{11}$. Esta dinámica que hurta la solución al problema y muestra la impotencia de los gobiernos ante la ciudadanía, sólo se transformará cuando exista una voluntad política clara de conceder a la sostenibilidad un rango de interés general similar al que ostentan los intereses económicos que orientan a la política mundial. No obstante, y a pesar de las evidencias científicas o de la fuerte presión ecologista, la realidad nos muestra que aún resta un largo camino hacia la sostenibilidad y que los mecanismos utilizados en el presente serán inútiles en las próximas décadas, si no se acomete con rigor un proceso de transformación que, por una parte, facilite la planificación de los mecanismos de mercado y que, por otra, permita elaborar un marco o un orden superior que señale, a todos los niveles, los límites trazados por la sostenibilidad.

\section{Bibliografía}

Aguilar, S. (1997). El reto del medio ambiente. Madrid: Alianza Universidad.

BECK, U. (1992). Risk society. Londres: SAGE Publications. En versión castellana: $L a$ sociedad del riesgo. Barcelona: Paidós, 1998.

Climent, V. (1998). «La percepción ambiental en el ámbito productivo». Revista Internacional de Sociología (RIS), 19-20. IESA-Andalucía: CSIC.

Climent, V. (1999). Producción y crisis ecológica: Los agentes sociales ante la problemática ambiental. Universitat de Barcelona.

Espluga, J. (2000). Respostes socials al risc tecnològic. Tesis doctoral, UAB.

GARCíA, E. (2004). Medio ambiente y sociedad. Madrid: Alianza Ensayo.

GARCIA FERRANDO, M. (1991). «Opinión pública y medio ambiente». Sistema, 104-105, p. $175-189$.

GidDENs, A. (1996). Más allá de la izquierda y la derecha. Madrid: Cátedra.

LEMKOW, L. (2002). Sociología ambiental. Barcelona: Icaria. Antrazyt, 177.

Mol, Arthur P. J. (1995). The refinement of Production: Ecological Modernization

Theory and the Chemical Industry. Utrecht, Holanda: International Books.

Sempere, J.; Riechmann, J. (2000). Sociología y medio ambiente. Madrid: Síntesis.

TÀBARA, D. (1996). La percepció dels problemes de medi ambient. Barcelona: Beta.

TÀBARA, D.; Polo, D.; LEMKOW, L. (2003). «Precaución, riesgo y sostenibilidad en los organismos agrícolas modificados genéticamente». Política y Sociedad, 40 (3): 81-103.

11. En la Conferencia de Río (1992), los países firmantes acordaron reducir, para el año 2000, la emisión de $\mathrm{CO}_{2}$ a los mismos niveles de 1990. En la conferencia de Berlín (1995), se constató el fracaso de esta medida y, salvo el compromiso de algunas naciones europeas para reducir voluntariamente sus emisiones, no se alcanzó ningún acuerdo de alto contenido. En la Conferencia de Kioto (1997), los resultados tampoco fueron muy halagüeños. Después de intensas negociaciones, los países desarrollados se comprometieron a reducir sus emisiones en un 5,2\% de media, respecto a los niveles de 1990 y 1995 , entre el 2008 y el 2010. El acuerdo afecta a seis gases y las cuotas fijadas contemplan una reducción del $8 \%$ para la UE y otros países europeos, un $7 \%$ para Canadá y EE.UU. (éste último no ha ratificado el protocolo) y un 6\% para Japón. Rusia queda obligada a estabilizar sus emisiones mientras que los países en vías de desarrollo podrán seguir incrementando sus emisiones hasta el 2010. 